\title{
IDENTIFIKASI PENYAKIT BURUNG PERKUTUT MENGGUNAKAN FORWARD CHAINING
}

\author{
Tri Hastono ${ }^{1}$, Sunggito Oyama ${ }^{2}$ \\ 1,2Program Sarjana Informatika, Universitas PGRI Yogyakarta \\ Jl. IKIP PGRI I Sonosewu No.117, (0274) 376808 \\ 1trihastono@upy.ac.id, 20yama@upy.ac.id
}

\begin{abstract}
Perkutut (Geopelia striata) is a bird that has a beautiful and unique voice. In ancient time, the perkutut was a pet of nobles. Based on some references, the keris makers incorporate the special characteristics of a perkutut bird is the prestige of the keris he made. The closeness of the keris to the Javanese community makes the perkutut bird has its own space in the hearts of the people. Nowadays, many people keep the birds as their pet because of their beautiful voice and their easy treatment. An easy treatment does not mean that the perkutut bird is resistant to disease. In this case, we need advice from the bird experts to treat the disease. This study provides a solution to identify the perkutut disease and its treatment. The method used in this research is forward chaining with depth-first search technique. The logic used in each is the AND logic. The object of this study was a local perkutut with 13 disease items and 19 disease symptoms. The results of testing on the proposed system indicate that the system can identify the disease of the Perkutut accurately.
\end{abstract}

Keywords: - identification, disease, perkutut, forward chaining

\begin{abstract}
Abstrak
Perkutut (Geopelia striata) adalah salah satu burung yang memiliki suara yang indah dan unik. Pada zaman dahulu, burung perkutut adalah burung peliharaan para ningrat atau bangsawan. Dan dari beberapa literatur, para empu dalam membuat keris memasukkan ciri khusus perkutut pada pamor keris yang dibuatnya. Kedekatan keris dengan masyarakat Jawa, membuat burung perkutut memiliki ruang sendiri dihati masyarakat. Sekarang ini, banyak yang memelihara burung perkutut karna keindahan suaranya dan perawatan yang terhitung mudah. Perawatan yang mudah bukan berarti burung perkutut kebal akan penyakit. Untuk itu diperlukan saran dari pakar burung perkutut untuk mengobati penyakitnya. Penelitian ini memberikan solusi untuk identifikasi penyakit burung perkutut beserta penanganannya. Metode yang digunakan pada penelitian adalah forward chaining dengan teknik penelusurannya adalah depth-first search. Adapun logika yang digunakan pada setiap rule adalah logika AND. Objek penelitian yang dipilih adalah burung perkutut lokal dengan item penyakit sebanyak 13 penyakit dan 19 gejala penyakit. Hasil pengujian pada sistem yang diusulkan menunjukan bahwa sistem dapat mengidentifikasi penyakit burung perkutut secara akurat.
\end{abstract}

Kata kunci: identifikasi, penyakit, perkutut, forward chaining 


\section{PENDAHULUAN}

\subsection{Latar belakang}

Burung perkutut (Geopelia Striata) adalah salah jenis burung yang tergolong suku burung merpati-merpatian (Columbidae). Secara umum ciri dari burung perkutut adalah memiliki bulu dengan warna dasar coklat keabu-abuan, bulu kepala dan leher berwarna abu-abu kebiru-biruan, terdapat pola garis melintang hitam putih pada bagian dada dan leher, dan memiliki panjang tubuh sekitar $25 \mathrm{~cm}$ (9 inci)[1].

Burung perkutut sudah lama dikenal orang. Zaman dahulu, Burung perkutut merupakan burung peliharaan orang-orang penting, seperti raja, ningrat atau bangsawan, pejabat kerajaan, dan pemuka masyarakat [1][2]. Sekarang ini pecinta burung perkutut merata disemua lapisan masyarakat. Keindahan suara burung perkutut menjadikan burung perkutut memiliki tempat sendiri dihati masyarakat [1][3][4].

Burung perkutut juga memberikan kontribusi yang besar pada kebudayaan [2][5][6]. Keris yang merupakan merupakan senjata tradisional masyarakat Jawa memiliki hubungan erat dengan burung perkutut. Banyak keris yang namanya berasal dari ciri fisik yang dimiliki burung perkutut. Hal tersebut dikarenakan pamor yang ada pada keris merupakan representasi dari ciri fisik (katuranggan) burung perkutut [5][6].

Burung perkutut pun ada dalam falsafah hidup masyarakat Jawa [7]. Cupu manik hasta gina adalah falsafah atau pedoman hidup yang dianut oleh masyarakat Jawa. Isi dari falsafah cupu manik hasta gina adalah mengenai kesempurnaan hidup. Kesempurnaan hidup seseorang akan tercapai jika 8 unsur terpenuhi. 8 unsur kesempurnaan hidup adalah wanita, garwa, wisma, turangga, curiga, kukila, waranggana, dan pradangga. Burung perkutut pada falsafah cupu manik hasta gina sendiri dilambangkan dengan kukila [2][7].

Terlepas dari falsafah masyarakat Jawa, burung perkutut adalah burung yang memiliki suara yang indah serta unik ketika bersuara atau "manggung". Suara burung perkutut dikatakan unik karena suara burung perkutut tidak bisa diisi atau diubah dengan suara burung lain layaknya burung ocehan dan suara burung perkutut satu dengan yang lain memiliki perbedaan1 [4].

Selain suara yang indah dan unik, perawatan burung perkutut relatif mudah tidak seperti burung yang lain [1][2]. Walaupun perwatanannya terhitung mudah, bukan berarti kebal akan penyakit. Bagi pemilik burung perkutut atau peternak perkutut tentu saja mengharapkan burung perkutut peliharaannya selalu sehat dan rajin manggung. Tapi ketika burung perkutut yang dipelihara terlihat tidak seperti biasanya, besar kemungkinan burung perkutut tersebut terkena suatu penyakit. Tidak semua obat bisa diberikan untuk mengobati penyakit burung perkutut, terlebih lagi burung perkutut tersebut adalah sudah menjadi burung kesayangan.

Penyakit burung perkutut harus ditangani oleh seorang yang betul-betul ahli mengenai penyakit burung perkutut. Ketersediaan pakar burung perkutut sangatlah terbatas. Dan berdasarkan permasalahan tersebut maka penelitian ini diusulkan. Penelitian ini memberikan jawaban terhadap identifikasi penyakit 
burung perkutut dengan cara menghadirkan pakar burung perkutut dalam bentuk aplikasi komputer. Metode yang digunakan pada penelitian adalah forward chaining dengan teknik penelusurannya adalah depth-first search. Adapun logika yang digunakan pada setiap rule adalah logika $A N D$. Dan objek penelitian yang dipilih adalah burung perkutut lokal dengan item penyakit sebanyak 13 penyakit dan 19 gejala penyakit.

\subsection{Tinjauan pustaka}

Terdapat beberapa penelitian terdahulu yang sudah dilakukan yang digunakan peneliti sebagai referensi.

Penelitian yang telah dilakukan Daniel Alexander Octavianus Turang [8] mengupas mengenai diagnose penyakit syaraf pusat menggunakan forward chaining dengan teknik penelusuran depth-first search. Item penyakit pada jaringan syaraf pusat sejumlah 12 penyakit dan gejala dari penyakitnya sebanyak 44. Platform yang dipilih pada penelitian adalah platform web. Hasil dari penelitian menunjukan sistem yang diusulkan sudah berjalan dengan baik.

Penelitian yang telah dilakukan oleh Bagus Fery Yanto dkk [9] membahas mengenai sistem pakar pada anak-anak dengan usia 2-5 bulan. Sistem pakar yang dirancang berbasis rule if-then dengan platform android. Data penyakit balita peneliti dapatkan dari proses wawancara dengan bidan. Data penyakit yang diperoleh dari proses wawancara sebanyak 18 penyakit. Hasil penelitian menunjukan sistem pakar yang dibangun sudah cukup baik dengan tingkat akurasi sebesar $82 \%$.

Penelitian yang dilakukan oleh Deddy Kusbianto [10] membahas mengenai sistem pakar identifikasi penyakit jerawat. Latar belakang dari penelitian adalah gejala yang hamper sama antara jerawat dengan yang mirip dengan jerawat. Metode yang dipilih oleh peneliti pada penelitian adalah metode Forward Chaining dengan platform desktop. Bahasa pemrograman yang digunakan pada perancangan adalah Visual Basic dengan basis data Maria DB. Data penyakit yang diperoleh dari pakar sejumlah 7 penyakit dengan gejala sebanyak 18 gejala. Tingkat akurasi dari sistem yang diusulkan sebesar $83.3 \%$.

Penelitian yang dilakukan oleh Doddy Teguh Yuwono [11] membahas mengenai kepakaran pada hama penyakit anggrek Coelogyne Pandurata. Coelogyne Pandurata merupakan salah satu endemik Kalimantan yang rentan penyakit. Metode yang digunakan pada penelitian adalah metode Forward Chaining dan Certainty Factor. Hasil kedua metode yang dipilih menghasilkan tingkat akurasi sebesar 93,0736\%.

Penelitian yang dilakukan Hasbi Sidiq Arfajsyah dkk [12] membahas mengenai sistem pakar untuk penyakit gigi dan mulut manusia. Sistem pakar yang dirancang berbasis rule dengan jumlah rule sebanyak 13 dan gejala dari penyakit sebanyak 44 gejala. Metode yang digunakan untuk yang dipilih pada penelitian ini adalah Forward Chainning. Sistem pakar yang dihasilkan menggunakan Android sebagai platform aplikasinya. Hasil dari penelitian yang telah dilakukan sebesar 93\% sangat baik dari pengguna. 
Penelitian yang dilakukan oleh Januardi Nasir [13] mengupas mengenai sistem pakar untuk penderita kepribadian dramatik. Latar belakang dari penelitian ini adalah rendahnya interaksi sosial bagi penderita kepribadian dramatik membuat semakin memperparah keadaan. Dengan adanya sistem pakar untuk penderita kepribadian dramatik diharapkan dapat membantu permasalahan dari penderita kepribadian dramatik. Sistem pakar yang dibangun menggunakan bahasa programan PHP dan MySQL. Dan metode yang digunakan pada penelitian adalah metode forward chaining. Secara umum sistem pakar yang dibangun memenuhi kebutuhan dari penderita kepribadian dramatik.

Penelitian yang dilakukan oleh Ona Maliki [14] membahas mengenai sistem pakar penentuan tipe perumahan. Latar belakang dari penelitian adalah susahnya berkonsultasi dengan seorang arsitektur. Dengan dibangunnya sistem pakar penentuan tipe perumahan diharapkan masalah tipe perumahan terselesaikan. Metode yang digunakan pada penelitian adalah metode forward chaining. Metode tersebut diemplementasikan pada Bahasa pemrograman PHP dan MySQL sebagai penyimpanan datanya. Hasil penelitian menunjukkan sistem pakar penentuan tipe perumahan sudah berjalan sesuai dengan harapan

\section{METODOLOGI PENELITIAN}

\subsection{Obyek penelitian}

Objek pada penelitian ini adalah burung perkutut lokal. Untuk mendapatkan data, peneliti melakukan penelitian burung perkutut lokal di 2 tempat, yaitu : daerah Bantul dan Daerah Sleman. Kedua daerah tersebut dipilih karena terdapat beberapa peternakan burung perkutut yang sudah cukup lama menggeluti kegiatan peternakan burung perkutut. Didaerah bantul, peneliti melakukan penelitian pada peternakan burung perkutut Ahmad Ghozali Bird Farm. Sedangkan didaerah Sleman, peneliti melakukan penelitian di 2 peternakan, yaitu JnJ Bird Farm dan Sungsang Bird Farm.

\subsection{Pengumpulan data penelitian}

Data pada penelitian ini ada 2 yaitu : data primer dan data sekunder. Data primer dari penelitian diperoleh pada saat proses wawancara dengan seoarang pakar hewan. Pakar yang dipilih adalah seorang dokter hewan yang berada dikota Yogyakarta. Drh Budi Pramono adalah seorang dokter hewan yang dijadikan sebagai sumber primer penelitian ini. Selain wawancara yang telah dilakukan dengan seorang pakar, peneliti juga melakukan wawancara dengan peternakpeternak burung perkutut yang merupakan pemilik dari peternakan burung perkutut.

Sedangkan data sekunder pada penelitian berasalah dari studi pustaka dari beberapa sumber tertulis. Sumber tertulis yang digunakan sebagai data skunder berupa publikasi ilmiah (jurnal, prosiding, dan website terpercaya) dan buku. Sumber data sekunder yang yang dipilih sebagai acuan adalah sumber yang terbaru dan isinya membahas secara khusus mengenai burung perkutut. 


\subsection{Alur penelitian}

Tahap-tahap dari penelitian ini secara umum ada 5, yaitu : pengumpulan data, tahap analisis kebutuhan, tahap perancangan, dan tahap pengujian. Pada tahap pengumpulan data dilakukan 2 proses yaitu studi literatur dan studi lapangan. Proses yang dilakukan pada tahap analisis kebutuhan adalah analisis kebutuhan system dan pengguna. Proses yang dilakukan pada tahap perancangan adalah desain prototipe, evaluasi prototipe, dan pembuatan aplikasi. Proses yang terjadi pada tahap pengujian adalah pengujian dan evaluasi system yang diusulkan. Gambar 1 dibawah ini adalah alur penelitian yang dilakukan

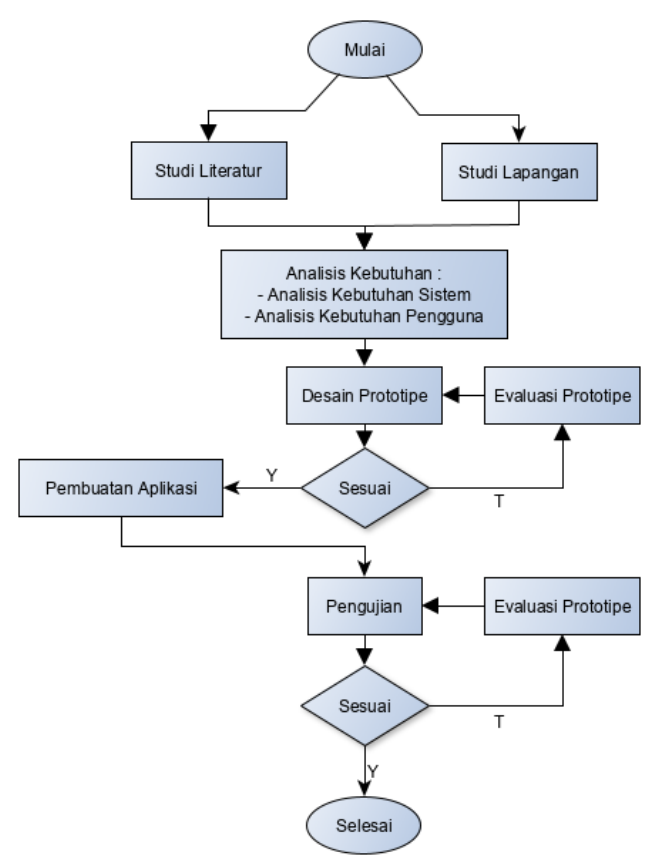

Gambar 1. Alur penelitian

\subsection{Forward chainning}

Forward chaining merupakan salah satu metode inferensi yang sering digunakan dalam menentukan jawaban terbaik dari suatu kasus. Forward chaining dimulai dengan data driven, maksudnya adalah pada forward chaining semua data dan aturan akan ditelusuri untuk mencapai tujuan/kesimpulan yang diinginkan [15][16]. Forward Chaining juga merupakan sebuah pendekatan untuk penelusuran guna menentukan kesimpulan yang dapat digambarkan secara logis sebagai aplikasi berulang dari modus ponens [16]. Gambar 2 dibawah ini adalah gambar ilustrasi dari forward chaining. 


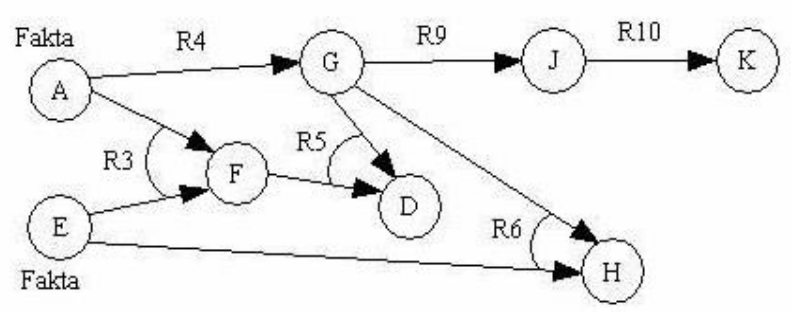

Gambar 2. Forward chainning

\subsection{Depth-first serach}

Depth-first search adalah sebuah algoritma perulangan yang memanfaatkan backtracking. Algoritma depth-first search ini melakukan pencarian secara mendalam disemua node. Pencarian mendalam yang dimaksud adalah pencarian ke bawah selama memungkinkan. Dan backtracking akan dilakukan jika dalam pencarian jika sudah tidak memungkinkan lagi. Proses backtracking dilakukan ke node terdekat dari jalur yang pertama dilewati [15][16]. Ilustrasi dari depth-first search dapat dilihat pada gambar 3.

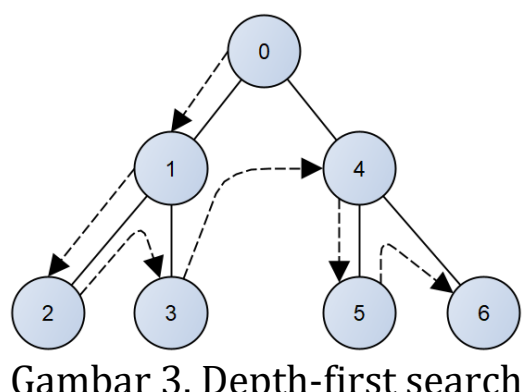

\section{HASIL DAN PEMBAHASAN}

\subsection{Akuisisi pengetahuan}

Berdasarkan hasil wawancara dengan pakar dan sumber data sekunder penelitian diperoleh data penyakit burung perkutut lokal beserta gejalanya. Adapun penyakit burung perkutut lokal ada 13 penyakit. Untuk data penyakit burung perkutut lokal disajikan pada tabel 1.

Tabel 1. Penyakit burung perkutut

\begin{tabular}{ll}
\hline Kode penyakit & Nama penyakit \\
\hline P1 & Kolera \\
P2 & Berak Darah (Koksidiosis) \\
P3 & Berak Kapur atau Berak Putih (Pullorum) \\
P4 & Cacingan \\
P5 & Stres \\
P6 & Pilek \\
P7 & Pilar atau cacar paruh (Diphteri) \\
P8 & Keracunan makanan \\
P9 & Pilar atau cacar mata \\
P10 & Pilar atau cacar kulit \\
\hline
\end{tabular}




\begin{tabular}{ll} 
P11 & Pilar atau cacar kaki \\
P12 & Pilar atau cacar darah (septikemia) \\
P13 & Bulu rontok \\
\hline
\end{tabular}

Setiap penyakit burung perkutut lokal tersebut memiliki gejala-gejala yang berbeda. Setelah dilakukan proses normalisasi data, gejala penyakit burung perkutut menjadi 19 gejala penyakit. Data gejala penyakit burung perkutut disajikan pada tabel 2 .

Tabel 2. Gejala penyakit burung perkutut

\begin{tabular}{|c|c|}
\hline $\begin{array}{l}\text { Kode } \\
\text { gejala }\end{array}$ & Gejala \\
\hline G1 & Keadaannya terlihat lemah dan lesu serta malas manggung \\
\hline G2 & Bulunya kusam, Badan cepat kurus, dan Kotorannya encer \\
\hline G3 & Lumpuh dan Kejang-kejang kemudian mati \\
\hline G4 & Warna Kotorannya kehijau-hijauan \\
\hline G5 & Warna Kotorannya merah \\
\hline G6 & Warna Kotorannya putih \\
\hline G7 & $\begin{array}{l}\text { Nafsu makan berkurang, Terlihat pucat, dan Susah terbang serta } \\
\text { Kotorannya berbau angit }\end{array}$ \\
\hline G8 & Merosot kondisi badannya \\
\hline G9 & $\begin{array}{l}\text { Makan minum tidak teratur, tidak banyak bergerak dan terlihat } \\
\text { lelah }\end{array}$ \\
\hline G10 & $\begin{array}{l}\text { Hidung mengeluarkan lendir, Mengkorok(bulu badan berdiri), } \\
\text { seperti mengantuk, muka bengkak kemerahan, dan sering } \\
\text { mengigil }\end{array}$ \\
\hline G11 & Terlihat sesak nafas \\
\hline G12 & $\begin{array}{l}\text { Bersin-bersin, hidung dan mulut mengeluarkan lendir, dan Lendir } \\
\text { yang mengering warnanya kuning kotor dan berbau busuk }\end{array}$ \\
\hline G13 & Batuk-batuk, Suara serak, dan Kejang-kejang lalu mati \\
\hline G14 & Mata bengkak dan tampak merah berair \\
\hline G15 & Terdapat bintil-bintil kuning bernanah pada kulit \\
\hline G16 & $\begin{array}{l}\text { Bintil-bintil yang pecah mengeluarkan cairan bercampur darah } \\
\text { dan lukanya berupa keropeng-keropeng merah kehitaman }\end{array}$ \\
\hline G17 & Persendian kaki bengkak dan kaki lumpuh \\
\hline G18 & Mati secara mendadak \\
\hline G19 & $\begin{array}{l}\text { Bulu badan rusak atau patah-patah serta berguguran (terutama } \\
\text { bulu punggung dan dada) }\end{array}$ \\
\hline
\end{tabular}

Dari data yang ditampilkan pada tabel 1 dan 2, maka dibuatlah rule atau aturan yang nantinya diaplikasikan pada system yang diusulkan. Rule dihasilkan ditampilkan pada tabel 3 dibawah ini. 
Tabel 3. Rule aplikasi

\begin{tabular}{ll}
\hline Kode rule & \multicolumn{1}{c}{ Kecepatan } \\
\hline $\mathrm{R}[1]$ & IF G1 AND G2 AND G3 AND G4 THEN P1 \\
$\mathrm{R}[2]$ & IF G1 AND G2 AND G3 AND G5 THEN P2 \\
$\mathrm{R}[3]$ & IF G1 AND G2 AND G3 AND G6 THEN P3 \\
$\mathrm{R}[4]$ & IF G1 AND G2 AND G7 THEN P4 \\
$\mathrm{R}[5]$ & IF G1 AND G8 AND G9 THEN P5 \\
$\mathrm{R}[6]$ & IF G1 AND G8 AND G10 THEN P6 \\
$\mathrm{R}[7]$ & IF G1 AND G11 AND G12 THEN P7 \\
$\mathrm{R}[8]$ & IF G1 AND G11 AND G13 THEN P8 \\
$\mathrm{R}[9]$ & IF G1 AND G14 THEN P9 \\
$\mathrm{R}[10]$ & IF G1 AND G15 AND G16 THEN P10 \\
$\mathrm{R}[11]$ & IF G1 AND G17 THEN P11 \\
$\mathrm{R}[12]$ & IF G1 AND G18 THEN P12 \\
$\mathrm{R}[13]$ & IF G19 THEN P13 \\
\hline
\end{tabular}

4.

Untuk pohon keputusan dari sistem yang diusulkan disajikan pada gambar

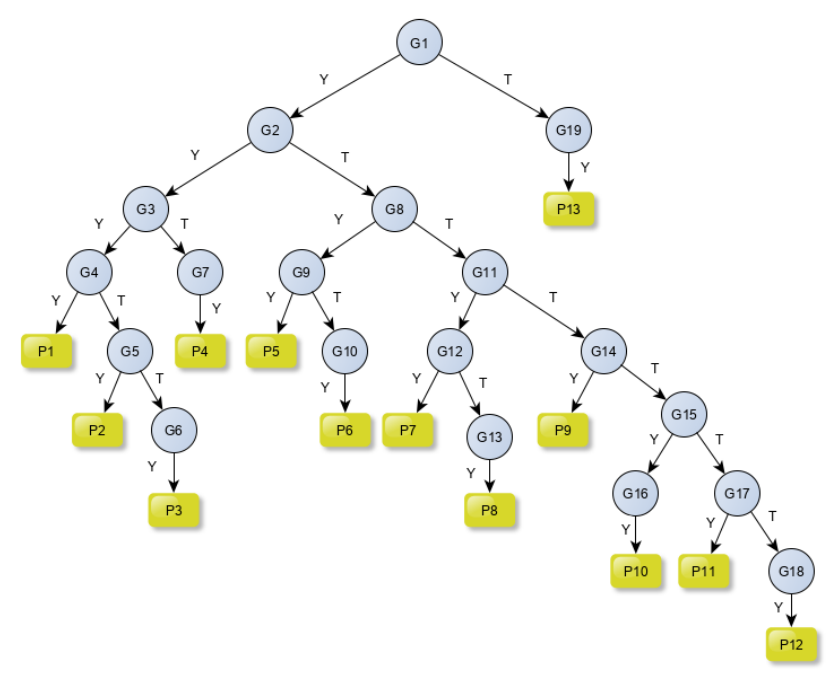

Gambar 4. Pohon keputusan penelitian

\subsection{Penerapan forward chaining dan depth-first search}

Pada penelitian ini pendekatan yang digunakan adalah forward chaining dengan teknik penelusuran depth-first search. Forward chaining bekerja berdasarkan informasi yang dimasukkan oleh pengguna aplikasi dari setiap pertanyaan yang dimunculkan sistem. Dengan teknik penelusuran depth-first search, penulusuran dilakukan dilakukan secara mendalam dari simpul atas kesimpul dibawahnya secara terurut.

Sebagai contoh untuk penyakit burung perkutut P1. Pertama kali system pakar akan menunculkan pertanyaan simpul G1("Keadaannya terlihat lemah dan lesu serta malas manggung") sesuai dengan gambar 4. Pada saat itu forward 
chaining akan menyiapkan mencoba menggambarkan kesimpulan dengan menyiapkan pertanyaan selanjutnya (simpul G2 dan G19). Dan ketika pengguna memberikan jawaban "y" dari pertanyaan G1, maka system pakar akan memunculkan pertanyaan G2 ("Bulunya kusam, Badan cepat kurus, dan Kotorannya encer"). Proses penggambaran kesimpulan dan penelusuran mendalam tersebut dilakukan sampai simpul atau node G4. Jawaban 'y' pengguna aplikasi ketika pertanyaan G4 muncul memberikan hasil berupa penyakit P1.

Tapi jika pada pertanyaan G4 dijawab ' $\mathrm{t}$ ' oleh pengguna aplikasi, maka proses backtracking dari teknik penelusuran dept-first search dijalankan, sehingga sistem akan mencari alternatif terdekat dari simpul G4 yaitu simpul G5 dan seterusnya. Proses backtracking juga akan dilakukan lagi pada simpul G6 penguna aplikasi masih menjawab ' $\mathrm{t}$ ', maka system pakar akan memunculkan pertanyaan simpul G7.

\subsection{Interface aplikasi}

Secara umum, aplikasi system pakar untuk identfikasi penyakit burung perkutut lokal terdapat 4 halaman. Halaman-halaman aplikasi tersebut adalah halaman depan aplikasi, halaman login pakar, halaman data pengetahuan dan data pakar, dan halaman konsultasi pengguna. Pada halaman depan terdapat 3 menu utama, yaitu menu konsultasi pengguna, menu pakar, dan menu keluar. Gambar 5 dibawah ini adalah gambar halaman depan aplikasi system pakar untuk identifikasi penyakit pada burung perkutut lokal.

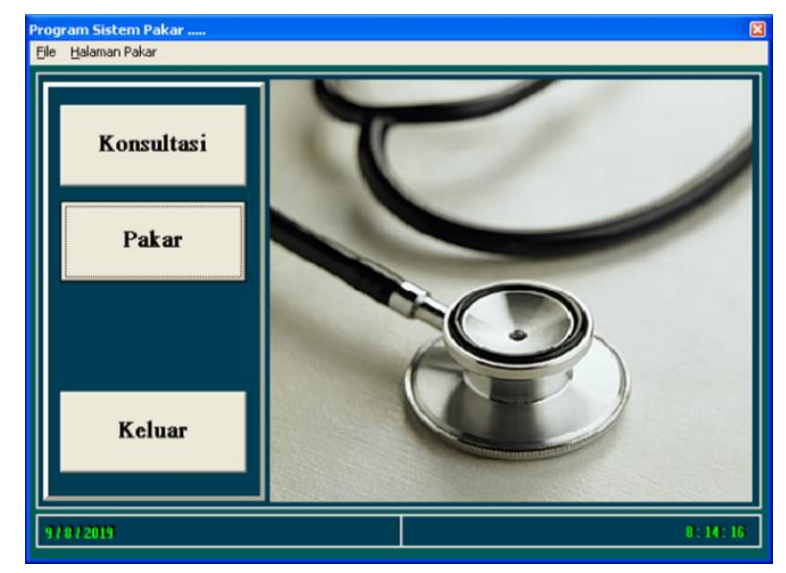

Gambar 5. Halaman depan aplikasi

Halaman login pakar adalah sebuah halaman yang digunakan autentifikasi seorang pakar. Halaman ini muncul ketika pengguna aplikasi memilih menu pakar pada halaman depan aplikasi system pakar untuk identifikasi penyakit pada burung perkutut lokal. Gambar 6 dibawah adalah gambar halaman login. 


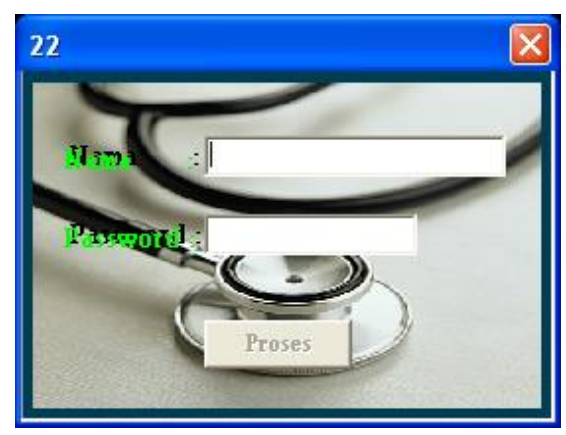

Gambar 6. Halaman login pakar

Halaman data pengetahuan dan data pakar adalah halaman yang digunakan pakar untuk melakukan update data pengetahuan dan data pakar. Gambar 7 dan 8 adalah gambar halaman data pengetahuan dan data pakar.

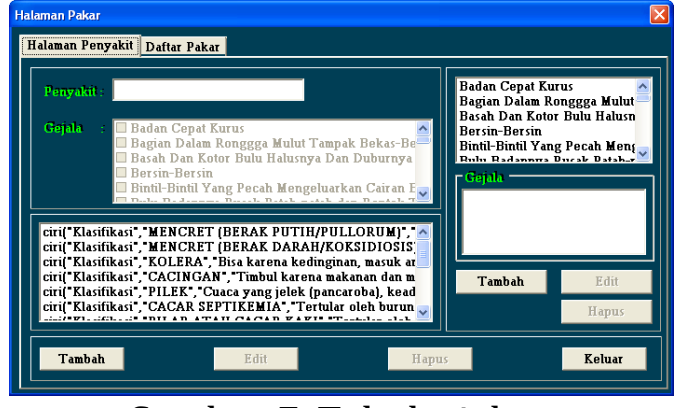

Gambar 7. Tabulasi data pengetahuan

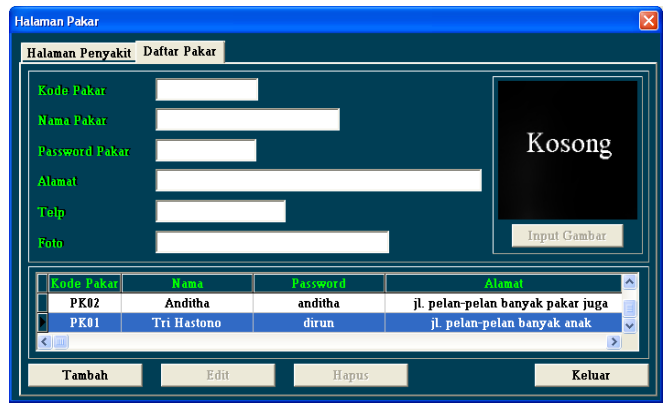

Gambar 8. Tabulasi data pakar

Halaman konsultasi adalah halaman yang digunakan pengguna aplikasi untuk melakukan konsultasi penyakit burung perkutut. Gambar 9, 10 dan 11 dibawah adalah gambar halaman konsultasi.

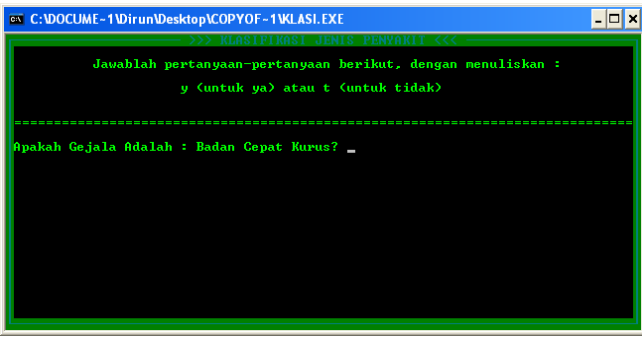

Gambar 9. Halaman konsultasi

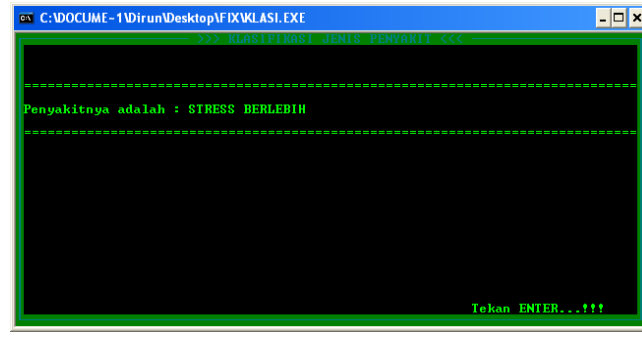

Gambar 8. Hasil identifikasi penyakit 1 


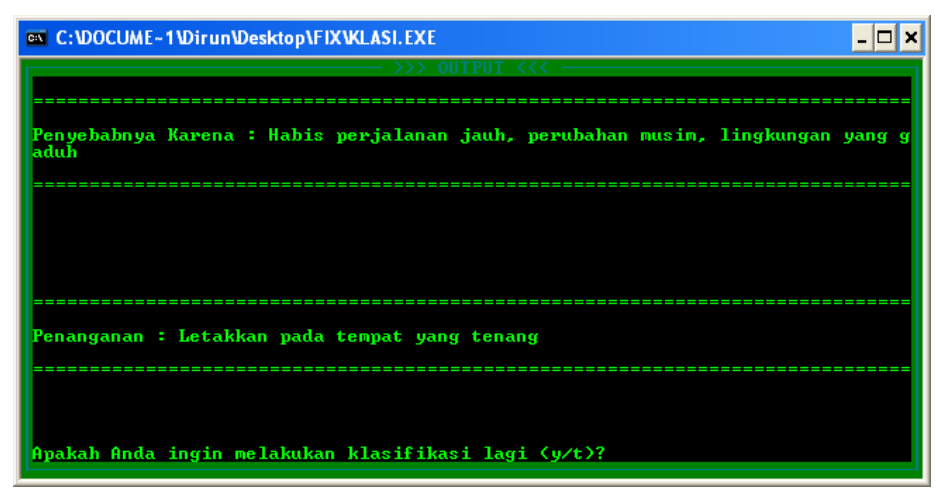

Gambar 11. Hasil identifikasi penyakit 2

\section{SIMPULAN}

Dari hasil pengujian terhadap system yang diusulkan menunjukkan bahwa system pakar untuk identifikasi penyakit pada burung perkutut lokal berjalan dengan baik dan akurat. Setiap item penyakit yang ada pada system pakar sudah sesuai dengan gejala yang dimilikinya. Begitu pula dengan data gejala penyakit yang telah dinormalisasi juga sudah sesuai dengan pengetahuan pakar.

Untuk penelitian selanjutnya diharapkan sudah bersifat online dan dengan platform yang lain. Logika yang digunakan pada setiap rule tidak lagi menggunakan logika AND, sehingga kemampuan sistem semakin baik. Kelengkapan data pengetahuan pakar merupakan kunci dari system pakar yang dibangun. Jadi sebaiknya data pengetahuan pakar diperbanyak, sehingga informasi yang didapatkan pengguna aplikasi terpenuhi.

\section{DAFTAR PUSTAKA}

[1] Sarwono, B., "Perkutut", Penebar Swadaya, Jakarta, 1997.

[2] Sanjaya, A. L., Purwantoro, A., \& Wahyuningsih, N., "Katurangganing Kutut", Ekspresi Seni : Jurnal Ilmu Pengetahuan dan Karya Seni, Vol. 19, No. 2, hal 174192, 2017.

[3] Purnamasari, D. K., "Evaluasi Nilai Nutrisi Pakan Dan Tingkat Preferensi Perkutut (Geopelia striata) Terhadap Pakan Yang Diberikan Pada Pemeliharaan Ex-Situ", BioWallacea, vol. 1, no. 1, hal 14-17, 2015.

[4] Rahmadina, R., "Pengaruh Jenis Makanan Pur, Biji-Bijian, Serangga Terhadap Perkembangan Bobot Tubuh Burung Perkutut (Geopelia Striata)", KLOROFIL, Vol 1, hal 78-82, 2018.

[5] Doyodipuro, K.H., "Keris Daya Magic-Manfaat-Tuah-Misteri”, Vol. I, Dahara Prize, Semarang, 2005.

[6] Wijayanto, W., \& Sudrajat, U., "Keris dalam Perspektif Keilmuan", Pusat Penelitian dan Pengembangan Kebudayaan Badan Pengembangan Sumber Daya Kebudayaan dan Pariwisata Kementrian Kebudayaan dan Pariwisata, Jakarta, 2011.

[7] Santosa, P., “Adedamar Wahyu : Pustaka Puisi Falsafah Budaya Jawa”, Vol. I, Azzagrafika, Yogyakarta, 2015. 
[8] Turang, D. A., "Aplikasi Sistem Pakar Berbasis Web Untuk Mendiagnosa Penyakit Syaraf Pusat Dengan Metode Forward Chaining", Klik, Vol. 5, no. 1, hal 87-97, 2018.

[9] Yanto, B. F., Werdiningsih, I., dan Purwanti, E., "Aplikasi Sistem Pakar Diagnosa Penyakit Pada Anak Bawah Lima Tahun Menggunakan Metode Forward Chaining", Journal of Information Systems Engineering and Business Intelligence, vol. 3, hal 61-67, 2016.

[10] Kusbianto, D., Ardiansyah, R., dan Hamadi, D. A., "Implementasi Sistem Pakar Forward Chaining Untuk Identifikasi Dan Tindakan Perawatan Jerawat Wajah", Jurnal Informatika Polinema, hal. 71-80, 2017.

[11] Yuwono, D. T., Fadlil, A., dan Sunardi, S., "Penerapan Metode Forward Chaining Dan Certainty Factor Pada Sistem Pakar Diagnosa Hama Anggrek Coelogyne Pandurata", KLIK, vol. 4, hal 136-145, 2017.

[12] Arfajsyah, H. S., Permana, I., dan Salisah, F. N., "Sistem Pakar Berbasis Android Untuk Diagnosa Penyakit Gigi Dan Mulut", Jurnal Ilmiah Rekayasa Dan Manajemen Sistem Informasi, vol. 4, no. 2, hal 110-117, 2018.

[13] Nasir, J., dan Jahro, J., "Sistem Pakar Konseling Dan Psikoterapi Masalah Kepribadian Dramatik Menggunakan Metode Forward Chaining Berbasis Web", RABIT, vol. 3, no. 1, hal 37-48, 2018.

[14] Maliki, O., dan Dangkua, F., "Sistem Pakar Tipe Perumahan Menggunakan Metode Forward Chaining", JURNAL INFORMATIKA UPGRIS, vol. 4, no. 2, hal 150-157, 2019.

[15] Arhami, M., "Konsep Dasar Sistem Pakar", Penerbit Andi, Yogyakarta, DIY, 2005.

[16] Rosnelly, R., "Sistem Pakar Konsep dan Teori", Andi Publisher, Yogyakarta, DIY, 2017.

[17] Bobzien, S., "The development of modus ponens in antiquity: From Aristotle to the 2nd century AD", Phronesis, Vol 47, hal 359-394, 2002. 